\title{
Dose-Response Association Between High- Density Lipoprotein Cholesterol and Stroke: A Systematic Review and Meta-Analysis of Prospective Cohort Studies
}

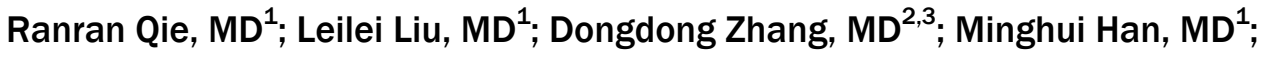 \\ Bingyuan Wang, MD, PhD ${ }^{3,4}$; Yang Zhao, MD, PhD ${ }^{1}$; Dechen Liu, MD ${ }^{1}$;

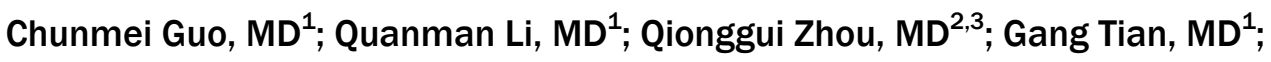 \\ Shengbing Huang, MD${ }^{1}$; Xiaoyan $\mathrm{Wu}, \mathrm{MD}^{2,3}$; Pei Qin, MD, PhD ${ }^{2,3}$; Jianxin Li, MD, PhD ${ }^{3,4}$; \\ Jie Cao, MD, PhD ${ }^{3,4}$; Ming Zhang, MD, PhD ${ }^{2,3}$; Jianfeng Huang, MD, $\mathrm{PhD}^{3,4}$;
}

Jie Lu, MD, $\mathrm{PhD}^{1}$; Dongsheng Hu, MD, $\mathrm{PhD}^{1}$

\begin{abstract}
Accessible Version: www.cdc.gov/pcd/issues/2021/20_0278.htm
Suggested citation for this article: Qie R, Liu L, Zhang D, Han M, Wang B, Zhao Y, et al. Dose-Response Association Between High-Density Lipoprotein Cholesterol and Stroke: A Systematic Review and Meta-Analysis of Prospective Cohort Studies. Prev Chronic Dis 2021;18:200278. DOI: https://doi.org/10.5888/ pcd18.200278.
\end{abstract}

\section{PEER REVIEWED}

\section{Summary}

What is already known on this subject?

Previous epidemiologic studies reported that HDL-C protected against the development of stroke. However, several recent cohort studies found a positive association between HDL-C level and intracerebral hemorrhage. Also, whether a dose-response association between HDL-C level and stroke subtypes exists remains unclear.

What is added by this report?

Our results showed an $18 \%$ reduction in the relative risk of total stroke and a $24 \%$ reduction for ischemic stroke, but a $21 \%$ increase in intracerebral hemorrhage per 1-mmol/L increase in HDL-C level.

What are the implications for public health practice?

Reasonable control of HDL-C level will prevent and control incident stroke. Our findings may facilitate the development and promotion of blood lipid prevention strategies aimed at reducing stroke risk.

\begin{abstract}
\section{Introduction}

Studies investigating the effect of high-density lipoprotein cholesterol (HDL-C) on stroke and stroke subtypes have reached inconsistent conclusions. The purpose of our study was to clarify the dose-response association between HDL-C level and risk of total stroke and stroke subtypes by a systematic review and metaanalysis.
\end{abstract}

\section{Methods}

We performed a systematic search of PubMed, Embase, and Web of Science databases through July 30, 2020, for prospective cohort studies that reported the HDL-C-stroke association and extracted the estimate that was adjusted for the greatest number of confounding factors. Restricted cubic splines were used to evaluate the linear and nonlinear dose-response associations.

\section{Results}

We included 29 articles, which reported on 62 prospective cohort studies including 900,501 study participants and 25,678 with stroke. The summary relative risk per 1-mmol/L increase in HDL$\mathrm{C}$ level for total stroke was $0.82\left(95 \% \mathrm{CI}, 0.76-0.89 ; I^{2}=42.9 \%\right.$; $\mathrm{n}=18)$; ischemic stroke (IS), $0.75\left(95 \%\right.$ CI, $0.69-0.82 ; I^{2}=$ $50.1 \% ; \mathrm{n}=22)$; intracerebral hemorrhage (ICH), $1.21(95 \% \mathrm{CI}$, $\left.1.04-1.42 ; I^{2}=33.4 \% ; \mathrm{n}=10\right)$; and subarachnoid hemorrhage (SAH), $0.98\left(95 \%\right.$ CI, $\left.0.96-1.00 ; I^{2}=0 \% ; \mathrm{n}=7\right)$. We found a linear inverse association between HDL-C level and risk of total 
stroke and SAH, a nonlinear inverse association for IS risk, but a linear positive association for ICH risk. The strength and the direction of the effect size estimate for total stroke, IS, ICH, and SAH remained stable for most subgroups. We found no publication bias with Begg's test and Egger's test for the association of HDL-C level with risk of total stroke, IS, and ICH.

\section{Conclusion}

A high HDL-C level is associated with reduced risk of total stroke and IS and an increased risk of ICH.

\section{Introduction}

Stroke is highly prevalent worldwide, and the number of people who experience stroke increased to more than 104.2 million in 2017 (1). From 1990 through 2017, the disability-adjusted lifeyears for stroke were about 132.0 million in 195 countries (2). Moreover, stroke is the second leading cause of death in the world, accounting for 6.2 million deaths globally in 2017. Of these deaths, about 2.7 million were due to ischemic stroke (IS), 3.0 million to intracerebral hemorrhage (ICH), and 0.5 million to subarachnoid hemorrhage (SAH) $(3,4)$. However, much of the stroke burden could be prevented by managing and controlling modifiable risk factors.

Many prospective cohort studies reported that a high-density lipoprotein cholesterol (HDL-C) level protected against the development of stroke (5-11). However, the "good cholesterol" label for HDL-C has been challenged by several recent randomized controlled trials demonstrating that HDL-C-elevating therapy increased the risk of cardiovascular diseases $(12,13)$. Thus, a full understanding of the effect of HDL-C level on stroke and stroke subtypes is warranted. Only one systematic review, conducted in 2008, examined the association between HDL-C level and risk of total stroke (14). Another meta-analysis in 2013 investigated the association between HDL-C level and risk of hemorrhagic stroke (15). However, up to 10 more cohort studies have been published recently on the association of HDL-C level with total stroke, ICH, and SAH, showing inconsistent results (9-11,16-24). No metaanalysis has been performed on the association of HDL-C level with IS, and a dose-response meta-analysis on the association of HDL-C level with total stroke and IS is lacking. We therefore performed this systematic review and dose-response meta-analysis of prospective cohort studies to quantitatively evaluate possible linear or nonlinear associations between baseline HDL-C level and risk of total stroke, IS, ICH, and SAH.

\section{Methods}

\section{Data sources and searches}

We followed the protocol for the Preferred Reporting Items for Systematic Reviews and Meta-Analyses (PRISMA) Statement for our meta-analysis (25). We conducted a systematic literature search of PubMed, Embase, and Web of Science databases for all reports of prospective cohort studies that examined the association between HDL-C level and stroke and were published through July 30, 2020, with no restriction on language. We also searched the reference lists of all related articles and reviews.

\section{Study selection}

Two authors (R.Q. and M.H.) independently searched articles, selected relevant studies based on their title and abstract, then evaluated these articles by reviewing the full text. Inclusion criteria for prospective cohort studies were as follows: 1) study participants were aged $\geq 18$ years; 2 ) the study investigated the association between HDL-C level and risk of stroke or stroke subtypes; 3 ) the study reported the effect estimates, relative risks (RRs), or hazard ratios (HRs), with $95 \%$ CIs for $\geq 3$ HDL-C categories or per-unit increase in HDL-C level; and 4) the study reported the number of cases, exposed person-years, or participant numbers in each category of HDL-C level. We excluded cross-sectional and casecontrol studies, commentaries, letters, reviews, meta-analyses, and studies with unusable data. If data from the same study were reported more than once, only the most recent and complete data were included.

\section{Data extraction and quality assessment}

R.Q. and L.L. independently extracted the following information from each study: first author, publication year, study name, study location, follow-up period, age range, sex, stroke and HDL-C assessment method, baseline levels of HDL-C, case number of percategory HDL-C exposure, total persons or person-years of percategory HDL-C exposure, reported RRs or HRs and 95\% CIs for each HDL-C category, and adjusted covariates. Included studies were assessed for quality according to the 9-point Newcastle-Ottawa Quality Assessment Scale (NOS) (26). Any discrepancy was resolved by discussion with a senior investigator (D.H.).

We classified stroke, which included embolic infarction, largeartery occlusive infarction, lacunar infarction, and unclassified, as $\mathrm{ICH}, \mathrm{SAH}$, and IS (10). Some studies include all types of stroke for analysis and we call it total stroke in this meta-analysis. The lowest HDL-C category was the reference. For studies that did not choose the lowest category as the reference category, we reformulated RRs to set the lowest HDL-C category as the reference (27).

\footnotetext{
The opinions expressed by authors contributing to this journal do not necessarily reflect the opinions of the U.S. Department of Health and Human Services, the Public Health Service, the Centers for Disease Control and Prevention, or the authors' affiliated institutions.
} 
When HDL-C levels were reported in milligrams per deciliter $(\mathrm{mg} / \mathrm{dL})$, we used the scaling factor of 38.67 to translate $1-\mathrm{mg} / \mathrm{dL}$ HDL-C to 1-mmol/L HDL-C. Studies that provided results separately for men and women or reported multiple stroke subtypes within an article were treated as independent studies. For studies reporting results separately for fatal and nonfatal stroke, we combined the RRs and then included the pooled RR in the metaanalysis.

\section{Data synthesis and analysis}

We considered the RR and 95\% CI of the effect size for all studies. The reported HRs in the primary studies were considered equal to RRs (28). We first used the DerSimonian and Laird random-effects model, which considers both within-study and between-study variation, to calculate summary RRs and 95\% CIs for high versus low HDL-C level (29). Studies reporting only a continuous risk estimate of stroke were excluded from our analysis. We then pooled the study-specific dose-response RRs and 95\% CIs per 1-mmol/L increase in HDL-C level (29).

We used generalized least squares regression to estimate the study-specific dose-response association (30). The natural RRs and CIs across categories of HDL-C level were used to compute study-specific slopes (linear trends) and 95\% CIs. A generalized least squares regression model estimates the linear dose-response coefficients and considers the covariance for each exposure category within each study because they are estimated relative to a common referent HDL-C level category. In this method, the distribution of cases and person-years, or cases and noncases, with the RRs and estimates of uncertainty (eg, CIs) for $\geq 3$ quantitative categories of exposure were required. If studies reported only the total number of cases or person-years, the number of person-years or cases in each category was obtained from the total number of person-years or cases divided by the number of reported categories. We assigned the mean, median, or midpoint of HDL-C level in each category to the corresponding risk estimate. When the lowest or highest categories were open-ended, we assumed the width of the category to be the same as the closest category when estimating the midpoint (31). For the studies already reporting a linear dose-response trend for per $\mathrm{n}-\mathrm{mmol} / \mathrm{L}$ increase in HDL-C level, we calculated the dose-response RRs per 1-mmol/L increase in HDL-C level with this formula: $R_{1}=\operatorname{EXP}\left(\operatorname{LN}\left(R_{n}\right) / n * 1\right)$, where $\mathrm{RR}_{1}$ represents the dose-response RRs for each $1-\mathrm{mmol} / \mathrm{L}$ increase in HDL-C level and $\mathrm{RR}_{\mathrm{n}}$ represents the dose-response RRs for each n-mmol/L increase in HDL-C level (EXP: exponential function; LN: log base e) (32). All study-specific dose-response RR estimates were then pooled by using the DerSimonian and Laird random effects model (29). With heterogeneity $\left(I^{2}\right)$ $\geq 50 \%$, a random-effects model was used to calculate the summary RRs and 95\% CIs; otherwise a fixed-effects model was used, which considered both within- and between-study variation. The Hartung-Knapp-Sidik-Jonkman method was used to evaluate the stability of results for $\mathrm{N}<10$ (33). A potential nonlinear association was examined by modeling HDL-C level by using restricted cubic splines with 3 knots located at the 25th, 50th, and 75th percentiles of the distribution (34). The $P$ for nonlinearity was calculated by testing the null hypothesis that the coefficient of the second spline is equal to zero (35).

Heterogeneity was assessed by Cochran Q and $I^{2}$ statistics (36). For the Q statistic, $P<.10$ was considered significant. For the $I^{2}$ statistic, $I^{2}$ values of $0 \%, 25 \%, 50 \%$, and $75 \%$ were considered to reflect no, low, moderate, and high heterogeneity, respectively. We also performed subgroup analyses by sex, region, follow-up period, publication year, sample size, and the covariates (alcohol drinking, education, body mass index, systolic blood pressure, physical activity, lipid-lowering medication use, and other lipid profile parameters) adjusted in the analysis.

A sensitivity analysis was performed to assess the influence of each individual study by omitting 1 study at a time and calculating a pooled estimate for the remainder of the studies (37). Potential publication bias was assessed with Egger's and Begg's tests $(38,39)$. Conversion from DerSimonian-Laird results to HartungKnapp-Sidik-Jonkman results involved using Microsoft Excel software (Microsoft Corp). Other analyses were conducted with Stata 12.1 (Stata Corp), and all tests were 2-sided with a significance level of $P<.05$.

\section{Results}

Literature search and study characteristics. Our literature search identified 7,366 articles; 1,113 were duplicates, leaving 6,253. After screening the titles and abstracts, we selected 201 potentially eligible articles. After detailed evaluation, we included 29 articles describing 62 prospective cohort studies in our metaanalysis with a total of 900,501 study participants of which 25,678 had stroke (5-11,16-24,40-52).

Eleven studies were conducted in Asia (including Iran and Israel) $(7,8,10,17,18,20,21,23,24,46,52), 9$ in the United States $(9,19,22,40,42,44,48-50), 7$ in Europe $(5,11,16,41,43,47,51)$, and 2 in Australia $(6,45)$. Three prospective cohorts included only men $(5,51,52)$, another 3 included only women $(8,40,49)$, and the rest included both sexes (Table 1). The mean NOS score was 8.24, which indicates the high quality of the articles included in the meta-analysis.

HDL-C level and risk of total stroke. To explore the association between HDL-C level and risk of total stroke, we examined 18 studies that included 256,427 participants overall and 12,328

The opinions expressed by authors contributing to this journal do not necessarily reflect the opinions of the U.S. Department of Health and Human Services, the Public Health Service, the Centers for Disease Control and Prevention, or the authors' affiliated institutions. 
people with stroke. We excluded 8 studies in comparing the highest versus lowest category of HDL-C because they provided only a continuous risk estimate. The pooled RR was $0.79(95 \% \mathrm{CI}$, $0.72-0.87 ; I^{2}=46.4 \% ; P_{\text {heterogeneity }}=.05$ ) (Table 2 ). The 18 studies were included in the dose-response analysis; the pooled RR for total stroke was $0.82(95 \% \mathrm{CI}, 0.76-0.89)$ per $1-\mathrm{mmol} / \mathrm{L}$ increase in HDL-C level, with low heterogeneity $\left(I^{2}=42.9 \% ; P_{\text {heterogeneity }}=\right.$ .03) (Table 3). We found a linear dose-response association between HDL-C level and risk of total stroke $\left(P_{\text {nonlinearity }}=.96\right)$ (Figure). No evidence of heterogeneity was detected between subgroups (Table 4). We observed an inverse association for most subgroups, except a nonsignificant association in studies of women, with a follow-up period of less than 10 years, without adjustment for physical activity or without adjustment for other lipid profile parameters (Table 4 ).
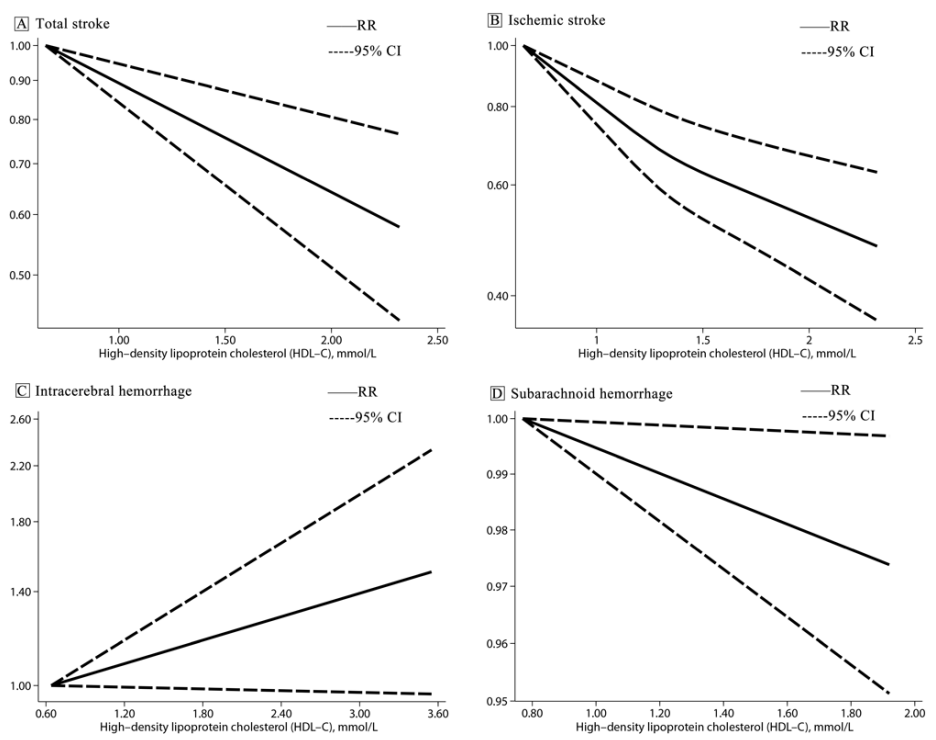

Figure. Linear dose-response association between high-density lipoprotein cholesterol and risk of stroke and stroke subtypes modeled with restricted cubic splines. Graph A shows total stroke; B, ischemic stroke; C, intracerebral hemorrhage; and D, subarachnoid hemorrhage.

HDL-C level and risk of IS. We included 10 studies consisting of a total of 706,482 participants and 19,047 people with stroke in the binary analysis of the association of IS risk with HDL-C level. The pooled RR was 0.75 (95\% CI, 0.68-0.82; $I^{2}=44.3 \%$; $P_{\text {heterogeneity }}=.06$; Table 2 ). Another 12 studies provided only a continuous risk estimate, so 22 studies were included in the dose-response analysis of IS risk. The pooled RR for IS was 0.75 (95\% CI, 0.69-0.82) per 1-mmol/L increase in HDL-C level, with low heterogeneity $\left(I^{2}=50.1 \% ; P_{\text {heterogeneity }}=.004\right)($ Table 3$)$. We found a nonlinear dose-response association between HDL-C level and IS risk $\left(P_{\text {nonlinearity }}=.13\right)$ (Figure). No evidence of heterogeneity was detected between subgroups (Table 4). Subgroup analyses showed a nonsignificant association in studies with a sample size of less than 10,000.

HDL-C level and risk of ICH. Ten studies consisting of 246,607 participants overall and 1,467 people with ICH were included in the analysis of HDL-C level and risk of ICH. The summary RR was $1.13\left(95 \% \mathrm{CI}, 0.93-1.36 ; I^{2}=29.9 \% ; P_{\text {heterogeneity }}=0.17\right)$ in the binary analysis (Table 2 ). The pooled results showed that risk of ICH was increased $26 \%$ per $1-\mathrm{mmol} / \mathrm{L}$ increase in HDL-C level (RR 1.21; 95\% CI, 1.04-1.42), with low heterogeneity $\left(I^{2}=\right.$ $33.4 \%, P_{\text {heterogeneity }}=0.14$ ) (Table 3 ). We found a linear dose-response association between HDL-C level and risk of ICH $\left(\mathrm{P}_{\text {nonlinearity }}=0.28\right)$ (Figure). The effect size and direction of the pooled estimates were robust for most subgroups.

HDL-C level and risk of SAH. Data from 7 studies that included a total of 127,935 participants of which 551 had SAH provided information on the association between HDL-C level and risk of SAH. The pooled RR was 0.69 (95\% CI, 0.50-0.95; $I^{2}=30.7 \%$; $\left.P_{\text {heterogeneity }}=0.19\right)$ (Table 2 ) in the binary analysis. With a per$1-\mathrm{mmol} / \mathrm{L}$ increase in HDL-C level, the pooled RR was $0.98(95 \%$ CI, $\left.0.96-1.00 ; I^{2}=0 \% ; P_{\text {heterogeneity }}=0.61\right)$ (Table 3 ). HartungKnapp-Sidik-Jonkman results showed that risk of SAH was decreased $14 \%$ per $1-\mathrm{mmol} / \mathrm{L}$ increase in HDL-C level (RR 0.86; 95\% CI, 0.75-0.98). We found a linear dose-response association between HDL-C level and risk of SAH $\left(P_{\text {nonlinearity }}=0.94\right)$ (Figure). The pooled estimates remained relatively stable on subgroup analyses.

Sensitivity analyses and publication bias. In sensitivity analyses, the results were robust when excluding one study at a time in the analysis of total stroke, IS, ICH, and SAH. We found no publication bias with Begg's test for risk of total stroke $(P=0.10)$, IS $(P=$ $.15)$, and ICH $(P=.86)$, and Egger's test for risk of total stroke ( $P$ $=.10)$, IS $(P=.31)$, and ICH $(P=.63)$. Publication bias was not assessed for the association between HDL-C level and SAH because of limited studies.

\section{Discussion}

We aimed to clarify the association between HDL-C level and risk of total stroke and stroke subtypes and found an inverse linear association between HDL-C level and risk of total stroke and IS. For each $1-\mathrm{mmol} / \mathrm{L}$ increase in HDL-C level, the risk of total stroke decreased by $18 \%$ and that of IS decreased by $24 \%$. For ICH, we found a positive linear association, with the risk of $\mathrm{ICH}$ increased $21 \%$ per $1-\mathrm{mmol} / \mathrm{L}$ increase in HDL-C level. In addition, we found a marginal inverse linear association between HDL-C level and risk of SAH.

The opinions expressed by authors contributing to this journal do not necessarily reflect the opinions of the U.S. Department of Health and Human Services, the Public Health Service, the Centers for Disease Control and Prevention, or the authors' affiliated institutions. 
Results of previous reviews and meta-analyses evaluating the association between HDL-C level and total stroke, ICH, and SAH were consistent with our study $(14,15)$. However, previous research suggesting a negative association between HDL-C level and total stroke was based on a review of 8 cohort studies and 3 case-control studies (14). Our review did not report the association between HDL-C level and stroke subtypes because of the limited data on that relationship (14). In the current meta-analysis, we quantitatively evaluated the possible linear or nonlinear association of HDL-C level with total stroke, IS, ICH, and SAH.

We found an inverse linear association between HDL-C level and risk of total stroke. The reduced risk of total stroke may be due to the anti-atherosclerotic effects of HDL-C (42). The oxidation of LDL is thought to play an important role in the development of atherogenesis. HDL is a powerful antioxidant that exists in the subintimal space of the artery at a concentration 20 times greater than that of LDL and thus plays an important role in preventing atherosclerosis by inhibiting LDL oxidation in the artery wall (53). Additionally, HDL-C may play a central role in the reverse transport of cholesterol, thereby preventing the accumulation of excess cholesterol in peripheral tissues and the processes that initiate atherogenesis (54). However, subgroup analyses by sex showed significantly decreased risk of total stroke in men but not in women. The reason behind such inference remains unknown, and future experimental studies are needed to explore the potential mechanism.

Among the 22 studies included for the association between HDLC level and IS risk in the current meta-analysis $(7,10,11,17,19-21,23,24,41,42,44,45,47,49-52,42,43,45,46,48,50$ $-53), 16$ showed an inverse association $(7,10,11,19,20,23,24$, $41,42,47,49-52), 10$ of which reached a significant level $(7,10,11,24,41,42,47,51)$ while the remaining 6 showed no statistical significance $(10,19,21,23,49,50)$. After pooling the 22 studies with a larger sample size, we observed a significant inverse nonlinear association between HDL-C level and IS. The main cause of IS is the formation of atherosclerotic plaque on the carotid artery wall (55). The anti-atherosclerotic effects and potent antiinflammatory properties of HDL-C could explain our finding of a significant inverse association between HDL-C level and risk of IS (42). The main protein in HDL-C, apolipoprotein A-1, had a direct protective effect on atherosclerosis in several animal experiments $(56,57)$. Besides, Kotur-Stevuljevic et al suggested that the increase in oxidative stress of HDL in patients after IS contributed to a decrease in the activity of the anti-oxidant enzyme paraoxonase 1 (55). Further research should confirm whether increasing HDL-C level through lifestyle changes or pharmacologic therapies will affect IS risk.
Compared with a previous meta-analysis of HDL-C level and hemorrhagic stroke (15), 5 cohort studies were additionally included in our meta-analysis of the association of HDL-C level and $\mathrm{ICH}$ risk. We found a positive linear association of HDL-C level and $\mathrm{ICH}$ risk, which agreed with the previous meta-analyses. The possible mechanisms are as follows. First, HDL also has an antithrombotic function. A high HDL-C level can increase the risk of ICH by promoting fibrinolysis (10), which was found to be associated with the inhibition of coagulation cascade and the stimulation of blood clot fibrinolysis (58). In addition, HDL attenuates platelet function by stimulating endothelial cells to produce nitric oxide and prostacyclin $(58,59)$.

Results of a previous meta-analysis reported a significant positive association between HDL-C level and SAH based on 2 cohort studies (15). Five cohort studies were additionally included in our meta-analysis of HDL-C level and SAH risk. We found a marginal inverse linear association between HDL-C level and SAH risk. More large-sample cohort studies are needed to firmly establish this association.

Our meta-analysis has several strengths. To our knowledge, this is the first meta-analysis to systematically examine the association between HDL-C level and risk of major stroke subtypes by using both binary and dose-response analyses. Also, all included studies had a prospective design, large sample size, and long followup. In addition, the high mean NOS score, 8.24, indicated a relatively high quality of the articles included.

Our meta-analysis also had several limitations. First, IS is a mixed term, including lacunar infarction, large-artery occlusive infarction, and embolic infarction. Only 1 study explored the distinction between IS subtypes, so we could not explore the association between HDL-C level and each IS subtype (10). Second, most included studies did not exclude participants using medication, which may have confounded the association of HDL-C level with risk of total stroke and stroke subtypes. Third, HDL-C level was measured only at baseline, so we could not consider the effect of HDL-C changes during follow-up. Finally, all included studies were observational, and we need further analyses based on randomized clinical trials for assessing the causality of HDL-C level on stroke.

The effects of HDL cholesterol levels on stroke risk vary by type of stroke. A high HDL-C level was associated with reduced risk of total stroke and IS, but an increased risk of ICH. Reasonable control of HDL-C level will prevent and control incident stroke. However, because the HDL particle is so complex, we do not know whether the particle size, number, HDL-C content, or functionality is the best marker of stroke risk. Future studies with information on potential mechanisms are needed.

The opinions expressed by authors contributing to this journal do not necessarily reflect the opinions of the U.S. Department of Health and Human Services, the Public Health Service, the Centers for Disease Control and Prevention, or the authors' affiliated institutions. 


\section{Acknowledgments}

The investigators thank the dedicated participants and all research staff members who participated in our study. This study was supported by the National Natural Science Foundation of China (grant nos. 81402752 and 81673260), the Natural Science Foundation of Guangdong Province in China (grant no. 2019A1515011183), and the Science and Technology Development Foundation of Shenzhen (grant nos. JCYJ 20170412110537191 and JCYJ20190808145805515). D.H., J.L., P.Q., B.W., and R.Q. originated and designed the study; R.Q., M.H., L.L., S.H., X.W., D.Z., and C.G. contributed to the extraction and analysis of data for the study; R.Q. drafted the paper; and Q.L., Q.Z., G.T., Y.Z., M.Z., D.L., J.L., J.C., and J.H. revised the paper critically for important content. All authors read and approved the final manuscript. No copyrighted material, surveys, instruments, or tools were used in our article. Additional information is available from the authors on request.

\section{Author Information}

Corresponding authors: Dongsheng Hu, Department of Epidemiology and Health Statistics, College of Public Health, Zhengzhou University, 100, Kexue Avenue, Gaoxin District, Zhengzhou, Henan 450001, People's Republic of China. Telephone: +86-755-86671951. E mail: dongshenghu563@126.com. Jie Lu, Department of Epidemiology and Health Statistics, College of Public Health, Zhengzhou University, Zhengzhou, Henan, People's Republic of China. Telephone: +86-371-67781247. Email: hanyaa800@zzu.edu.cn.

Author Affiliations: ${ }^{1}$ Department of Epidemiology and Health Statistics, College of Public Health, Zhengzhou University, Zhengzhou, Henan, People's Republic of China. ${ }^{2}$ School of Public Health, Shenzhen University Health Science Center, Shenzhen, Guangdong, People's Republic of China. ${ }^{3}$ Study Team of Shenzhen's Sanming Project, The Affiliated Luohu Hospital of Shenzhen University Health Science Center, Shenzhen, Guangdong, People's Republic of China. ${ }^{4}$ Department of Epidemiology, Fuwai Hospital, National Center for Cardiovascular Diseases, Chinese Academy of Medical Sciences and Peking Union Medical College, Beijing, People's Republic of China.

\section{References}

1. GBD 2017 Disease and Injury Incidence and Prevalence Collaborators. Global, regional, and national incidence, prevalence, and years lived with disability for 354 diseases and injuries for 195 countries and territories, 1990-2017: a systematic analysis for the Global Burden of Disease Study 2017. Lancet 2018;392(10159):1789-858. . Erratum in: Lancet 2019;22;393(10190):e44. doi: 10.1016/S0140-6736(19)31047

2. GBD 2017 DALYs and HALE Collaborators. Global, regional, and national disability-adjusted life-years (DALYs) for 359 diseases and injuries and healthy life expectancy (HALE) for 195 countries and territories, 1990-2017: a systematic analysis for the Global Burden of Disease Study 2017. Lancet 2018; 392(10159):1859-922. Erratum in Lancet 2019;22; 393(10190):e44. doi: 10.1016/S0140-6736(19)31043-8.

3. GBD 2017 Causes of Death Collaborators. Global, regional, and national age-sex-specific mortality for 282 causes of death in 195 countries and territories, 1980-2017: a systematic analysis for the Global Burden of Disease Study 2017. Lancet 2018;392(10159):1736-88.

4. Campbell BCV, De Silva DA, Macleod MR, Coutts SB, Schwamm LH, Davis SM, et al. Ischaemic stroke. Nat Rev Dis Primers 2019;5(1):70.

5. Wannamethee SG, Shaper AG, Ebrahim S. HDL-cholesterol, total cholesterol, and the risk of stroke in middle-aged British men. Stroke 2000;31(8):1882-8.

6. Simons LA, Simons J, Friedlander Y, McCallum J. Cholesterol and other lipids predict coronary heart disease and ischaemic stroke in the elderly, but only in those below 70 years. Atherosclerosis 2001;159(1):201-8.

7. Soyama Y, Miura K, Morikawa Y, Nishijo M, Nakanishi Y, Naruse Y, et al.; Oyabe Study. High-density lipoprotein cholesterol and risk of stroke in Japanese men and women: the Oyabe Study. Stroke 2003;34(4):863-8.

8. Curb JD, Abbott RD, Rodriguez BL, Masaki KH, Chen R, Popper JS, et al. High density lipoprotein cholesterol and the risk of stroke in elderly men: the Honolulu heart program. Am J Epidemiol 2004;160(2):150-7.

9. Reina SA, Llabre MM, Allison MA, Wilkins JT, Mendez AJ, Arnan MK, et al. HDL cholesterol and stroke risk: the MultiEthnic Study of Atherosclerosis. Atherosclerosis 2015; 243(1):314-9.

10. Saito I, Yamagishi K, Kokubo Y, Yatsuya H, Iso H, Sawada N, et al. Association of high-density lipoprotein cholesterol concentration with different types of stroke and coronary heart disease: the Japan Public Health Center-based prospective (JPHC) study. Atherosclerosis 2017;265:147-54.

\footnotetext{
The opinions expressed by authors contributing to this journal do not necessarily reflect the opinions of the U.S. Department of Health and Human Services, the Public Health Service, the Centers for Disease Control and Prevention, or the authors' affiliated institutions.
} 
11. Zhang Y, Tuomilehto J, Jousilahti P, Wang Y, Antikainen R, $\mathrm{Hu}$ G. Total and high-density lipoprotein cholesterol and stroke risk. Stroke 2012;43(7):1768-74.

12. Barter PJ, Caulfield M, Eriksson M, Grundy SM, Kastelein JJ, Komajda M, et al.; ILLUMINATE Investigators. Effects of torcetrapib in patients at high risk for coronary events. N Engl J Med 2007;357(21):2109-22.

13. Landray MJ, Haynes R, Hopewell JC, Parish S, Aung T, Tomson J, et al.; HPS2-THRIVE Collaborative Group. Effects of extended-release niacin with laropiprant in high-risk patients. N Engl J Med 2014;371(3):203-12.

14. Amarenco P, Labreuche J, Touboul PJ. High-density lipoprotein-cholesterol and risk of stroke and carotid atherosclerosis: a systematic review. Atherosclerosis 2008; 196(2):489-96.

15. Wang X, Dong Y, Qi X, Huang C, Hou L. Cholesterol levels and risk of hemorrhagic stroke: a systematic review and metaanalysis. Stroke 2013;44(7):1833-9.

16. Hamer M, Batty GD, Stamatakis E, Kivimaki M. Comparison of risk factors for fatal stroke and ischemic heart disease: a prospective follow up of the health survey for England. Atherosclerosis 2011;219(2):807-10.

17. Tohidi M, Mohebi R, Cheraghi L, Hajsheikholeslami F, Aref $\mathrm{S}$, Nouri S, et al. Lipid profile components and incident cerebrovascular events versus coronary heart disease; the result of 9 years follow-up in Tehran Lipid and Glucose Study. Clin Biochem 2013;46(9):716-21.

18. Aalami Harandi S, Sarrafzadegan N, Sadeghi M, Talaei M, Dianatkhah M, Oveisgharan S, et al. Do cardiometabolic risk factors relative risks differ for the occurrence of ischemic heart disease and stroke? Res Cardiovasc Med 2016;5(1):e30619.

19. Glasser SP, Mosher A, Howard G, Banach M. What is the association of lipid levels and incident stroke? Int J Cardiol 2016;220:890-4.

20. Hirata A, Okamura T, Sugiyama D, Kuwabara K, Kadota A, Fujiyoshi A, et al.; NIPPON DATA90 Research Group. The relationship between very high levels of serum high-density lipoprotein cholesterol and cause-specific mortality in a 20 year follow-up study of Japanese general population. J Atheroscler Thromb 2016;23(7):800-9.

21. Liu X, Yan L, Xue F. The associations of lipids and lipid ratios with stroke: a prospective cohort study. J Clin Hypertens (Greenwich) 2019;21(1):127-35.

22. Zhang Y, Vittinghoff E, Pletcher MJ, Allen NB, Zeki Al Hazzouri A, Yaffe K, et al. Associations of blood pressure and cholesterol levels during young adulthood with later cardiovascular events. J Am Coll Cardiol 2019; 74(3):330-41.
23. Watanabe J, Kakehi E, Kotani K, Kayaba K, Nakamura Y, Ishikawa S. High-density lipoprotein cholesterol and risk of stroke subtypes: Jichi Medical School Cohort Study. Asia Pac J Public Health 2020;32(1):27-34.

24. Gu X, Li Y, Chen S, Yang X, Liu F, Li Y, et al. Association of lipids with ischemic and hemorrhagic stroke: a prospective cohort study among 267500 Chinese. Stroke 2019; 50(12):3376-84.

25. Stroup DF, Berlin JA, Morton SC, Olkin I, Williamson GD, Rennie D, et al. Meta-analysis of observational studies in epidemiology: a proposal for reporting. JAMA 2000; 283(15):2008-12.

26. The Newcastle-Ottawa Scale (NOS) for assessing the quality of non-randomized studies in meta-analysis. Ottawa Health Research Institute. http://www.ohri.ca/programs/clinical_ epidemiology/oxford.htm. Accessed January 9, 2019.

27. Hamling J, Lee P, Weitkunat R, Ambühl M. Facilitating metaanalyses by deriving relative effect and precision estimates for alternative comparisons from a set of estimates presented by exposure level or disease category. Stat Med 2008; 27(7):954-70.

28. Orsini N, Li R, Wolk A, Khudyakov P, Spiegelman D. Metaanalysis for linear and nonlinear dose-response relations: examples, an evaluation of approximations, and software. Am J Epidemiol 2012;175(1):66-73.

29. DerSimonian R, Laird N. Meta-analysis in clinical trials. Control Clin Trials 1986;7(3):177-88.

30. Orsini N, Bellocco RSG, Greenland S. Generalized least squares for trend estimation of summarized dose-response data. Stata J 2006;6(1):40-57.

31. Ren Y, Liu Y, Sun XZ, Wang BY, Zhao Y, Liu DC, et al. Chocolate consumption and risk of cardiovascular diseases: a meta-analysis of prospective studies. Heart 2019;105(1):49-55.

32. Liu X, Zhang D, Liu Y, Sun X, Han C, Wang B, et al. Doseresponse association between physical activity and incident hypertension: a systematic review and meta-analysis of cohort studies. Hypertension 2017;69(5):813-20.

33. IntHout J, Ioannidis JPA, Borm GF. The Hartung-KnappSidik-Jonkman method for random effects meta-analysis is straightforward and considerably outperforms the standard DerSimonian-Laird method. BMC Med Res Methodol 2014; 14(1):25.

34. Greenland S. Dose-response and trend analysis in epidemiology: alternatives to categorical analysis. Epidemiology 1995;6(4):356-65.

35. Royston P. A strategy for modelling the effect of a continuous covariate in medicine and epidemiology. Stat Med 2000; 19(14):1831-47.

36. Higgins JP, Thompson SG, Deeks JJ, Altman DG. Measuring inconsistency in meta-analyses. BMJ 2003;327(7414):557-60.

The opinions expressed by authors contributing to this journal do not necessarily reflect the opinions of the U.S. Department of Health and Human Services, the Public Health Service, the Centers for Disease Control and Prevention, or the authors' affiliated institutions. 
37. Rotenstein LS, Ramos MA, Torre M, Segal JB, Peluso MJ, Guille C, et al. Prevalence of depression, depressive symptoms, and suicidal ideation among medical students: a systematic review and meta-analysis. JAMA 2016 ; 316(21):2214-36.

38. Begg CB, Mazumdar M. Operating characteristics of a rank correlation test for publication bias. Biometrics 1994; 50(4):1088-101.

39. Egger M, Smith GD, Schneider M, Minder C. Bias in metaanalysis detected by a simple, graphical test. BMJ 1997; 315(7109):629-34.

40. Rist PM, Buring JE, Ridker PM, Kase CS, Kurth T, Rexrode KM. Lipid levels and the risk of hemorrhagic stroke among women. Neurology 2019;92(19):e2286-94.

41. Vangen-Lønne AM, Wilsgaard T, Johnsen SH, Løchen ML, Njølstad I, Mathiesen EB. Declining incidence of ischemic stroke: what is the impact of changing risk factors? The Tromsø Study 1995 to 2012. Stroke 2017;48(3):544-50.

42. Pikula A, Beiser AS, Wang J, Himali JJ, Kelly-Hayes M, Kase $\mathrm{CS}$, et al. Lipid and lipoprotein measurements and the risk of ischemic vascular events: Framingham Study. Neurology 2015;84(5):472-9.

43. Wieberdink RG, Poels MM, Vernooij MW, Koudstaal PJ, Hofman A, van der Lugt A, et al. Serum lipid levels and the risk of intracerebral hemorrhage: the Rotterdam Study. Arterioscler Thromb Vasc Biol 2011;31(12):2982-9.

44. Willey JZ, Xu Q, Boden-Albala B, Paik MC, Moon YP, Sacco $\mathrm{RL}$, et al. Lipid profile components and risk of ischemic stroke: the Northern Manhattan Study (NOMAS). Arch Neurol 2009;66(11):1400-6.

45. Simons LA, Simons J, Friedlander Y, McCallum J. A comparison of risk factors for coronary heart disease and ischaemic stroke: the Dubbo study of Australian elderly. Heart Lung Circ 2009;18(5):330-3.

46. Noda H, Iso H, Irie F, Sairenchi T, Ohtaka E, Doi M, et al. Low-density lipoprotein cholesterol concentrations and death due to intraparenchymal hemorrhage: the Ibaraki Prefectural Health Study. Circulation 2009;119(16):2136-45.

47. Holme I, Aastveit AH, Hammar N, Jungner I, Walldius G. Relationships between lipoprotein components and risk of ischaemic and haemorrhagic stroke in the Apolipoprotein MOrtality RISk study (AMORIS). J Intern Med 2009; 265(2):275-87.

48. Sturgeon JD, Folsom AR, Longstreth WT Jr, Shahar E, Rosamond WD, Cushman M. Risk factors for intracerebral hemorrhage in a pooled prospective study. Stroke 2007; 38(10):2718-25.

49. Kurth T, Everett BM, Buring JE, Kase CS, Ridker PM, Gaziano JM. Lipid levels and the risk of ischemic stroke in women. Neurology 2007;68(8):556-62.
50. Psaty BM, Anderson M, Kronmal RA, Tracy RP, Orchard T, Fried LP, et al. The association between lipid levels and the risks of incident myocardial infarction, stroke, and total mortality: the Cardiovascular Health Study. J Am Geriatr Soc 2004;52(10):1639-47.

51. Leppälä JM, Virtamo J, Fogelholm R, Albanes D, Heinonen OP. Different risk factors for different stroke subtypes: association of blood pressure, cholesterol, and antioxidants. Stroke 1999;30(12):2535-40.

52. Tanne D, Yaari S, Goldbourt U. High-density lipoprotein cholesterol and risk of ischemic stroke mortality. A 21-year follow-up of 8586 men from the Israeli Ischemic Heart Disease Study. Stroke 1997;28(1):83-7.

53. Mackness MI, Abbott C, Arrol S, Durrington PN. The role of high-density lipoprotein and lipid-soluble antioxidant vitamins in inhibiting low-density lipoprotein oxidation. Biochem J 1993;294(Pt 3):829-34.

54. Barter PJ, Rye KA. Molecular mechanisms of reverse cholesterol transport. Curr Opin Lipidol 1996;7(2):82-7.

55. Kotur-Stevuljevic J, Bogavac-Stanojevic N, Jelic-Ivanovic Z, Stefanovic A, Gojkovic T, Joksic J, et al. Oxidative stress and paraoxonase 1 status in acute ischemic stroke patients. Atherosclerosis 2015;241(1):192-8.

56. Benoit P, Emmanuel F, Caillaud JM, Bassinet L, Castro G, Gallix P, et al. Somatic gene transfer of human ApoA-I inhibits atherosclerosis progression in mouse models. Circulation 1999; 99(1):105-10.

57. Tangirala RK, Tsukamoto K, Chun SH, Usher D, Puré E, Rader DJ. Regression of atherosclerosis induced by liverdirected gene transfer of apolipoprotein A-I in mice. Circulation 1999;100(17):1816-22.

58. van der Stoep M, Korporaal SJ, Van Eck M. High-density lipoprotein as a modulator of platelet and coagulation responses. Cardiovasc Res 2014;103(3):362-71.

59. Calkin AC, Drew BG, Ono A, Duffy SJ, Gordon MV, Schoenwaelder SM, et al. Reconstituted high-density lipoprotein attenuates platelet function in individuals with type 2 diabetes mellitus by promoting cholesterol efflux. Circulation 2009;120(21):2095-104.

The opinions expressed by authors contributing to this journal do not necessarily reflect the opinions of the U.S. Department of Health and Human Services, the Public Health Service, the Centers for Disease Control and Prevention, or the authors' affiliated institutions. 


\section{Tables}

Table 1. Characteristics of Prospective Cohort Studies Reviewed, Dose-Response Association Between High-Density Lipoprotein Cholesterol and Stroke ${ }^{a}$

\begin{tabular}{|c|c|c|c|c|c|c|c|}
\hline Study & Country & Year & Age, y (SD) ${ }^{b}$ & Follow-up, y & $\begin{array}{c}\text { Sample Size, } \\
\text { N (\% Men) }\end{array}$ & Main Outcomes & NOS $^{c}$ \\
\hline Watanabe et al (23) & Japan & 2020 & $55.0(13.4)$ & 10.7 & 11,027 (38.9) & $\begin{array}{l}\text { Total stroke, IS, } \\
\text { ICH, SAH }\end{array}$ & 9 \\
\hline Zhang et al (22) & US & 2019 & 52.7 & 17 & $36,030(44.5)$ & Total stroke & 8 \\
\hline Gu et al (24) & China & 2019 & $50.4(11.6)$ & $6-19$ & $267,500(59.6)$ & IS & 9 \\
\hline Rist et al (40) & US & 2019 & $\geq 45$ & 19.3 & $27,937(0)$ & $\mathrm{ICH}, \mathrm{SAH}$ & 9 \\
\hline Liu et al (21) & China & 2019 & $20-80$ & 3.6 & 42,005 (61.9) & Total stroke, IS & 8 \\
\hline Saito et al (10) & Japan & 2017 & $40-69$ & 15 & $30,736(34.4)$ & $\begin{array}{l}\text { Total stroke, IS, } \\
\text { ICH, SAH }\end{array}$ & 8 \\
\hline Anne et al (41) & Norway & 2017 & $\geq 30$ & 12.8 & $27,936(47.4)$ & IS & 9 \\
\hline Harandi et al (18) & Iran & 2016 & $\geq 35$ & 10 & $6,323(\mathrm{NA})$ & Total stroke & 8 \\
\hline Glasser et al (19) & US & 2016 & $\geq 45$ & 6.9 & $23,867(45.0)$ & Total stroke, IS & 8 \\
\hline Hirata et al (20) & Japan & 2016 & $\geq 30$ & 18 & $7,019(42.0)$ & $\begin{array}{l}\text { Fatal total stroke, } \\
\text { fatal IS }\end{array}$ & 9 \\
\hline Pikula et al (42) & US & 2015 & $64(10)$ & 9 & $6,276(44.0)$ & IS & 8 \\
\hline Reina et al (9) & US & 2015 & $45-84$ & 9.5 & $6,814(47.0)$ & Total stroke & 8 \\
\hline Tohidi et al (17) & Iran & 2013 & $\geq 50$ & 9.1 & $2,620(46.0)$ & Total stroke, IS & 8 \\
\hline Zhang et al (11) & Finland & 2012 & $25-74$ & 20.1 & 58,235 (NA) & $\begin{array}{l}\text { Total stroke, IS, } \\
\text { ICH, SAH }\end{array}$ & 8 \\
\hline Wieberdink et al (43) & Netherlands & 2011 & $58.8-68.5$ & 9.7 & 5,773 (NA) & $\mathrm{ICH}$ & 9 \\
\hline Hamer et al (16) & England & 2011 & NA & $\mathrm{NA}$ & $13,778(N A)$ & Fatal total stroke & 7 \\
\hline Simons et al (45) & Australia & 2009 & $\geq 60$ & 16 & $2,805(44.0)$ & IS & 8 \\
\hline Willey et al (44) & US & 2009 & $68.8(10.3)$ & 7.5 & $2,940(36.5)$ & IS & 7 \\
\hline Noda et al (46) & Japan & 2009 & $40-79$ & 10 & 91,219 (33.8) & Fatal ICH & 9 \\
\hline Holme et al (47) & Sweden & 2009 & $30-85$ & 11.8 & $148,600(56.5)$ & IS & 8 \\
\hline Sturgeon et al (48) & US & 2007 & $\geq 45$ & 13.5 & $21,680(44.2)$ & $\mathrm{ICH}$ & 7 \\
\hline Kurth et al (49) & US & 2007 & $\geq 45$ & 11 & $27,937(0)$ & IS & 9 \\
\hline Psaty et al (50) & US & 2004 & $\geq 65$ & 7.5 & $4,885(40.0)$ & IS & 8 \\
\hline Curb et al (8) & Japan & 2004 & $71-93$ & 6.3 & $2,444(0)$ & Total stroke & 9 \\
\hline Soyama et al (7) & Japan & 2003 & $35-79$ & 10 & $4,989(30.5)$ & Total stroke & 9 \\
\hline Simons et al (6) & Australia & 2001 & $\geq 60$ & 10.8 & $2,805(44.0)$ & Total stroke & 8 \\
\hline Wannamethee et al (5) & England & 2000 & $40-59$ & 16.8 & $7,735(100)$ & Total stroke & 9 \\
\hline Leppala et al (51) & Finland & 1999 & $50-69$ & 6 & $28,519(100.0)$ & $\mathrm{ICH}, \mathrm{SAH}$ & 7 \\
\hline Tanne et al (52) & Israel & 1997 & $\geq 42$ & 21 & $8,586(100.0)$ & Fatal IS & 8 \\
\hline
\end{tabular}

Abbreviations: ICH, intracerebral hemorrhage; IS, ischemic stroke; NA, not available; NOS, Newcastle-Ottawa Scale; SAH, subarachnoid hemorrhage.

${ }^{a}$ Based on a systematic search of publications on PubMed, Embase, and Web of Science databases through July 30, 2020.

${ }^{b}$ Some articles reported mean age and SDs of included participants, and other articles reported only age range.

${ }^{\mathrm{c}}$ The Newcastle-Ottawa Scale (NOS) for assessing the quality of nonrandomized studies in meta-analysis (26).

The opinions expressed by authors contributing to this journal do not necessarily reflect the opinions of the U.S. Department of Health and Human Services, the Public Health Service, the Centers for Disease Control and Prevention, or the authors' affiliated institutions. 
Table 2. Risk Of Stroke And Stroke Subtypes With Highest Versus Lowest High-Density Lipoprotein Cholesterol, Systematic Review and Meta-Analysis of Prospective Cohort Studies

\begin{tabular}{|c|c|c|c|c|}
\hline Study (Reference Citation) & Sex & Study Year & Relative Risk (95\% Cl) & Weight (\%) ${ }^{a}$ \\
\hline \multicolumn{5}{|l|}{ Total stroke } \\
\hline Watanabe et al (23) & Men and women & 2020 & $0.68(0.49-0.95)$ & 8.63 \\
\hline Zhang et al (22) & Men and women & 2019 & $0.78(0.63-0.96)$ & 21.31 \\
\hline Saito et al (10) & Men & 2017 & $0.78(0.61-0.99)$ & 16.12 \\
\hline Saito et al (10) & Women & 2017 & $0.93(0.73-1.17)$ & 16.99 \\
\hline Hirata et al (20) & Men and women & 2016 & $1.39(0.67-2.89)$ & 1.77 \\
\hline Zhang et al (11) & Men & 2012 & $0.98(0.75-1.27)$ & 13.63 \\
\hline Zhang et al (11) & Women & 2012 & $0.70(0.53-0.93)$ & 11.96 \\
\hline Curb et al (8) & Men & 2000 & $0.37(0.17-0.81)$ & 1.55 \\
\hline Soyama et al (7) & Men and women & 2003 & $0.35(0.16-0.74)$ & 1.61 \\
\hline Wannamethee et al (5) & Men & 2000 & $0.68(0.46-0.99)$ & 6.44 \\
\hline Overall $^{b}$ & - & - & $0.79(0.72-9.87)$ & 100.0 \\
\hline \multicolumn{5}{|l|}{ Ischemic stroke } \\
\hline Watanabe et al (23) & Men and women & 2020 & $0.75(0.50-1.12)$ & 4.89 \\
\hline Gu et al (24) & Men and women & 2019 & $0.79(0.69-0.90)$ & 45.06 \\
\hline Saito et al (10) & Men & 2017 & $0.72(0.53-0.98)$ & 8.42 \\
\hline Saito et al (10) & Women & 2017 & $0.73(0.53-1.01)$ & 7.65 \\
\hline Tohidi et al (17) & Men and women & 2017 & $1.25(0.48-3.29)$ & 0.86 \\
\hline Zhang et al (11) & Men & 2012 & $1.05(0.77-1.42)$ & 8.49 \\
\hline Zhang et al (11) & Women & 2012 & $0.55(0.40-0.76)$ & 7.72 \\
\hline Kurth et al (49) & Women & 2007 & $0.82(0.55-1.23)$ & 4.91 \\
\hline Soyama et al (7) & Men and women & 2003 & $0.34(0.14-0.86)$ & 0.97 \\
\hline Leppala et al (51) & Men & 1999 & $0.59(0.45-0.77)$ & 11.03 \\
\hline Overall $^{\mathrm{C}}$ & - & - & $0.75(0.68-0.82)$ & 100.0 \\
\hline \multicolumn{5}{|l|}{ Intracerebral hemorrhage } \\
\hline Watanabe et al (23) & Men and women & 2020 & $0.53(0.25-1.14)$ & 6.05 \\
\hline Rist et al (40) & Women & 2019 & $0.98(0.45-2.13)$ & 5.76 \\
\hline Saito et al (10) & Men & 2017 & $0.81(0.52-1.28)$ & 17.16 \\
\hline Saito et al (10) & Women & 2017 & $1.72(1.08-2.74)$ & 16.06 \\
\hline Zhang et al (11) & Men & 2012 & $0.98(0.52-1.86)$ & 8.57 \\
\hline Zhang et al (11) & Women & 2012 & $2.14(0.91-5.05)$ & 4.74 \\
\hline Wieberdink et al (43) & Men and women & 2011 & $1.29(0.48-3.45)$ & 3.58 \\
\hline Noda et al (46) & Men and women & 2009 & $0.98(0.62-1.53)$ & 17.06 \\
\hline Sturgeon et al (48) & Men and women & 2007 & $1.39(0.62-2.25)$ & 15.05 \\
\hline
\end{tabular}

Abbreviation:-, not applicable.

${ }^{\mathrm{a}}$ Weight $=$ the proportion of the result of each article in the summary results.

$\mathrm{b} I^{2}=46.4 \% ; P=.05$.

$c I^{2}=44.3 \% ; P=0.06$.

$\mathrm{d} I^{2}=29.9 \% ; P=0.17$.

e $I^{2}=30.7 \% ; P=0.19$. 
(continued)

Table 2. Risk Of Stroke And Stroke Subtypes With Highest Versus Lowest High-Density Lipoprotein Cholesterol, Systematic Review and Meta-Analysis of Prospective Cohort Studies

\begin{tabular}{|c|c|c|c|c|}
\hline Study (Reference Citation) & Sex & Study Year & Relative Risk (95\% Cl) & Weight (\%) ${ }^{a}$ \\
\hline Leppala et al (51) & Men & 1999 & $1.33(0.62-2.85)$ & 5.98 \\
\hline Overall $^{d}$ & - & - & $1.13(0.93-1.36)$ & 100.0 \\
\hline
\end{tabular}

Subarachnoid hemorrhage

\begin{tabular}{|c|c|c|c|c|}
\hline Watanabe et al (23) & Men and women & 2020 & $0.64(0.27-1.55)$ & 13.18 \\
\hline Rist et al (40) & Women & 2019 & $1.01(0.33-3.08)$ & 8.07 \\
\hline Saito et al (10) & Men & 2017 & $1.23(0.47-3.24)$ & 10.80 \\
\hline Saito et al (10) & Women & 2017 & $0.73(0.40-1.34)$ & 27.55 \\
\hline Zhang et al (11) & Men & 2012 & $0.56(0.25-1.25)$ & 15.55 \\
\hline Zhang et al (11) & Women & 2012 & $1.27(0.50-3.28)$ & 11.38 \\
\hline Leppala et al (51) & Men & 1999 & $0.26(0.11-0.62)$ & 13.47 \\
\hline Overall $^{e}$ & - & - & $0.69(0.50-0.95)$ & 100.0 \\
\hline
\end{tabular}

Abbreviation:-, not applicable.

${ }^{a}$ Weight $=$ the proportion of the result of each article in the summary results.

b $I^{2}=46.4 \% ; P=.05$.

${ }^{c} I^{2}=44.3 \% ; P=0.06$.

d $I^{2}=29.9 \% ; P=0.17$.

$\mathrm{e} I^{2}=30.7 \% ; P=0.19$. 
Table 3. Relative Risk For Stroke And Stroke Subtypes in Relation to High-Density Lipoprotein Cholesterol Levels, Systematic Review and Meta-Analysis of Prospective Cohort Studies

\begin{tabular}{|c|c|c|c|c|}
\hline Study & Sex & Year & Relative Risk $(95 \% \mathrm{Cl})^{a}$ & Weight (\%) $)^{b}$ \\
\hline \multicolumn{5}{|l|}{ Total stroke } \\
\hline Watanabe et al (23) & Men and women & 2020 & $0.69(0.50-0.95)$ & 6.12 \\
\hline Zhang et al (22) & Men and women & 2019 & $0.81(0.67-0.96)$ & 19.49 \\
\hline Liu et al (21) & Men & 2019 & $0.86(0.62-1.19)$ & 5.93 \\
\hline Liu et al (21) & Women & 2019 & $1.19(0.73-1.94)$ & 2.64 \\
\hline Saito et al (10) & Men & 2017 & $0.75(0.58-0.97)$ & 9.38 \\
\hline Saito et al (10) & Women & 2017 & $0.92(0.71-1.19)$ & 9.34 \\
\hline Harandi et al (18) & Men and women & 2016 & $0.92(0.63-1.34)$ & 4.43 \\
\hline Glasseret al (19) & Men and women & 2016 & $0.93(0.78-1.10)$ & 21.24 \\
\hline Hirata et al (20) & Men and women & 2016 & $0.86(0.38-1.93)$ & 0.95 \\
\hline Reina et al (9) & Men and women & 2015 & $0.56(0.31-0.99)$ & 1.90 \\
\hline Tohidi et al (17) & Men and women & 2013 & $1.11(0.44-2.78)$ & 0.74 \\
\hline Zhang et al (11) & Men & 2012 & $1.01(0.66-1.53)$ & 3.60 \\
\hline Zhang et al (11) & Women & 2012 & $0.47(0.30-0.74)$ & 3.21 \\
\hline Hamer et al (16) & Men and women & 2011 & $1.13(0.75-1.68)$ & 3.88 \\
\hline Curb et al (8) & Men & 2004 & $0.20(0.06-0.72)$ & 0.39 \\
\hline Soyama et al (7) & Men and women & 2003 & $0.48(0.25-0.93)$ & 1.46 \\
\hline Simons et al (6) & Men and women & 2001 & $0.63(0.42-0.95)$ & 3.83 \\
\hline Wannamethee et al (5) & Men & 2000 & $0.48(0.25-0.93)$ & 1.46 \\
\hline Overall $^{\mathrm{C}}$ & - & - & $0.82(0.76-0.89)$ & 100.0 \\
\hline \multicolumn{5}{|l|}{ Ischemic stroke } \\
\hline Watanabe et al (23) & Men and women & 2020 & $0.76(0.51-1.12)$ & 3.55 \\
\hline Gu et al (24) & Men and women & 2019 & $0.75(0.67-0.83)$ & 10.89 \\
\hline Liu et al (21) & Men & 2019 & $0.83(0.57-1.21)$ & 3.74 \\
\hline Liu et al (21) & Women & 2019 & $1.14(0.67-1.93)$ & 2.21 \\
\hline Saito et al (10) & Men & 2017 & $0.68(0.49-1.01)$ & 4.48 \\
\hline Saito et al (10) & Women & 2017 & $0.70(0.49-1.01)$ & 3.98 \\
\hline Anne et al (41) & Men and women & 2017 & $0.78(0.66-0.92)$ & 8.80 \\
\hline Glasser et al (19) & Men and women & 2016 & $0.88(0.72-1.07)$ & 7.65 \\
\hline Hirata et al (20) & Men and women & 2016 & $1.15(0.65-2.04)$ & 1.94 \\
\hline Pikula et al (42) & Men and women & 2015 & $0.51(0.37-0.70)$ & 4.71 \\
\hline Tohidi et al (17) & Men and women & 2013 & $1.44(0.54-3.84)$ & 0.73 \\
\hline Zhang et al (11) & Men & 2012 & $1.02(0.62-1.66)$ & 2.47 \\
\hline
\end{tabular}

Abbreviation:-, not applicable.

a subtypes per 1-mmol/L increase in high-density lipoprotein cholesterol

${ }^{\mathrm{b}}$ Weights are from random effects analysis.

c $I^{2}=42.9 \% ; P=.03$.

d $I^{2}=50.1 \% ; P=.004$.

$\mathrm{e} I^{2}=33.4 \% ; P=.14$.

$\mathrm{f} I^{2}=0.0 \% ; P=.61$.

The opinions expressed by authors contributing to this journal do not necessarily reflect the opinions of the U.S. Department of Health and Human Services, the Public Health Service, the Centers for Disease Control and Prevention, or the authors' affiliated institutions. 
(continued)

Table 3. Relative Risk For Stroke And Stroke Subtypes in Relation to High-Density Lipoprotein Cholesterol Levels, Systematic Review and Meta-Analysis of Prospective Cohort Studies

\begin{tabular}{|c|c|c|c|c|}
\hline Study & Sex & Year & Relative Risk $(95 \% \mathrm{Cl})^{a}$ & Weight (\%) $)^{b}$ \\
\hline Zhang et al (11) & Women & 2010 & $0.35(0.21-0.59)$ & 2.29 \\
\hline Simons et al (45) & Men and women & 2010 & $1.10(0.65-1.87)$ & 2.21 \\
\hline Willey et al (44) & Men and women & 2009 & $1.08(0.67-1.66)$ & 2.80 \\
\hline Holme et al (47) & Men & 2009 & $0.79(0.71-0.86)$ & 11.26 \\
\hline Holme et al (47) & Women & 2009 & $0.67(0.59-0.73)$ & 10.91 \\
\hline Kurth et al (49) & Women & 2007 & $0.83(0.53-1.30)$ & 2.90 \\
\hline Psaty et al (50) & Men and women & 2004 & $0.81(0.60-1.10)$ & 4.90 \\
\hline Soyama et al (7) & Men and women & 2003 & $0.45(0.21-1.00)$ & 1.09 \\
\hline Leppala et al (51) & Men & 1999 & $0.54(0.39-0.75)$ & 4.49 \\
\hline Tanne et al (52) & Men & 1997 & $0.55(0.31-0.93)$ & 2.04 \\
\hline Overall $^{\mathrm{d}}$ & - & - & $0.75(0.69-0.82)$ & 100.0 \\
\hline \multicolumn{5}{|c|}{ Intracerebral hemorrhage } \\
\hline Watanabe et al (23) & Men and women & 2020 & $0.59(0.28-1.21)$ & 4.72 \\
\hline Rist et al (40) & Women & 2019 & $0.99(0.47-2.09)$ & 4.53 \\
\hline Saito et al (10) & Men & 2017 & $0.79(0.49-1.28)$ & 10.91 \\
\hline Saito et al (10) & Women & 2017 & $1.69(1.05-2.73)$ & 11.01 \\
\hline Zhang et al (11) & Men & 2012 & $1.13(0.41-3.07)$ & 2.51 \\
\hline Zhang et al (11) & Women & 2012 & $2.64(0.67-10.42)$ & 1.34 \\
\hline Wieberdink et al (43) & Men and women & 2011 & $1.16(0.84-1.61)$ & 23.91 \\
\hline Noda et al (46) & Men and women & 2009 & $1.19(0.82-1.74)$ & 17.75 \\
\hline Sturgeon et al (48) & Men and women & 2007 & $1.69(1.17-2.41)$ & 19.23 \\
\hline Leppala et al (51) & Men & 1999 & $1.08(0.49-2.36)$ & 4.10 \\
\hline Overall $^{\mathrm{e}}$ & - & - & $1.21(1.04-1.42)$ & 100.0 \\
\hline \multicolumn{5}{|c|}{ Subarachnoid hemorrhage } \\
\hline Watanabe et al (23) & Men and women & 2020 & $0.64(0.28-1.49)$ & 0.06 \\
\hline Rist et al (40) & Women & 2019 & $1.02(0.35-2.97)$ & 0.04 \\
\hline Saito et al (10) & Men & 2017 & $1.53(0.53-4.41)$ & 0.04 \\
\hline Saito et al (10) & Women & 2017 & $0.98(0.96-1.00)$ & 99.79 \\
\hline Zhang et al (11) & Men & 2012 & $0.67(0.19-2.35)$ & 0.03 \\
\hline Zhang et al (11) & Women & 2012 & $1.09(0.24-4.91)$ & 0.02 \\
\hline Leppala et al (51) & Men & 1999 & $0.41(0.14-1.23)$ & 0.03 \\
\hline Overall $^{f}$ & - & - & $0.98(0.96-1.00)$ & 100.0 \\
\hline
\end{tabular}

Abbreviation:-, not applicable.

a subtypes per 1-mmol/L increase in high-density lipoprotein cholesterol

${ }^{\mathrm{b}}$ Weights are from random effects analysis.

c $I^{2}=42.9 \% ; P=.03$.

$\mathrm{d} I^{2}=50.1 \% ; P=.004$.

$\mathrm{e} I^{2}=33.4 \% ; P=.14$.

$\mathrm{f} I^{2}=0.0 \% ; P=.61$.

The opinions expressed by authors contributing to this journal do not necessarily reflect the opinions of the U.S. Department of Health and Human Services, the Public Health Service, the Centers for Disease Control and Prevention, or the authors' affiliated institutions. 
Table 4. Dose-Response Subgroup Analyses of Association Between High-Density Lipoprotein Cholesterol and Risk of Total Stroke and Ischemic Stroke, Systematic Review and Meta-Analysis of Prospective Cohort Studies

\begin{tabular}{|c|c|c|c|c|c|c|c|c|}
\hline \multirow[b]{2}{*}{ Characteristics } & \multicolumn{4}{|c|}{ Total Stroke } & \multicolumn{4}{|c|}{ Ischemic Stroke } \\
\hline & No. of Studies & Relative Risk $(95 \% \mathrm{Cl})$ & $I^{2}$ & $P$ Value $^{\mathrm{a}}$ & No. of Studies & Relative Risk (95\% Cl) & $I^{2}$ & $P$ Value $^{\mathrm{a}}$ \\
\hline All studies & 18 & $0.82(0.76-0.89)$ & 42.9 & .03 & 22 & $0.75(0.69-0.82)$ & 50.1 & .004 \\
\hline \multicolumn{9}{|l|}{ Sex } \\
\hline Men/women & 7 & $0.82(0.70-0.96)$ & 41.8 & .11 & 8 & $0.78(0.68-0.89)$ & 51.0 & .046 \\
\hline Men & 8 & $0.79(0.64-0.99)$ & 31.9 & .17 & 9 & $0.76(0.65-0.90)$ & 39.6 & .10 \\
\hline Women & 6 & $0.74(0.52-1.04)$ & 60.0 & .03 & 8 & $0.71(0.56-0.88)$ & 49.7 & .05 \\
\hline \multicolumn{9}{|l|}{ Region } \\
\hline Asian & 10 & $0.81(0.70-0.95)$ & 28.6 & .18 & 10 & $0.76(0.68-0.85)$ & 8.0 & .37 \\
\hline Non-Asian & 8 & $0.77(0.63-0.93)$ & 59.2 & .02 & 12 & $0.74(0.66-0.84)$ & 65.8 & .001 \\
\hline \multicolumn{9}{|l|}{ Follow-up period } \\
\hline$<10$ years & 7 & $0.92(0.81-1.05)$ & 44.4 & .10 & 9 & $0.78(0.66-0.91)$ & 57.7 & .03 \\
\hline$\geq 10$ years & 11 & $0.77(0.70-0.85)$ & 31.3 & .15 & 13 & $0.74(0.66-0.82)$ & 47.2 & .03 \\
\hline \multicolumn{9}{|l|}{ Publication year } \\
\hline$\leq 2010$ & 4 & $0.53(0.39-0.72)$ & 4.6 & .37 & 8 & $0.72(0.63-0.82)$ & 51.1 & .05 \\
\hline$>2010$ & 14 & $0.85(0.78-0.92)$ & 27.0 & .17 & 14 & $0.77(0.68-0.87)$ & 51.5 & .01 \\
\hline \multicolumn{9}{|l|}{ Sample size } \\
\hline$<10,000$ & 8 & $0.67(0.55-0.82)$ & 30.4 & .19 & 8 & $0.79(0.60-1.05)$ & 59.0 & .004 \\
\hline$\geq 10,000$ & 10 & $0.85(0.78-0.93)$ & 41.2 & .08 & 14 & $0.75(0.68-0.81)$ & 47.9 & .02 \\
\hline \multicolumn{9}{|l|}{ Alcohol drinking } \\
\hline No & 6 & $0.88(0.79-0.98)$ & 6.5 & .38 & 8 & $0.74(0.66-0.83)$ & 59.1 & .02 \\
\hline Yes & 12 & $0.76(0.68-0.85)$ & 48.0 & .03 & 14 & $0.76(0.66-0.88)$ & 47.8 & .02 \\
\hline \multicolumn{9}{|l|}{ Education } \\
\hline No & 13 & $0.80(0.71-0.91)$ & 31.8 & .12 & 15 & $0.74(0.68-0.81)$ & 34.6 & .09 \\
\hline Yes & 5 & $0.74(0.52-1.05)$ & 71.3 & .02 & 7 & $0.76(0.62-0.95)$ & 70.4 & .002 \\
\hline \multicolumn{9}{|l|}{ Body mass index } \\
\hline No & 6 & $0.89(0.78-1.02)$ & 29.2 & .22 & 6 & $0.80(0.70-0.91)$ & 59.4 & .03 \\
\hline Yes & 12 & $0.78(0.71-0.87)$ & 46.3 & .04 & 16 & $0.72(0.64-0.81)$ & 48.6 & .02 \\
\hline \multicolumn{9}{|c|}{ Systolic blood pressure } \\
\hline No & 6 & $0.82(0.71-0.94)$ & 45.3 & .10 & 6 & $0.74(0.65-0.84)$ & 67.6 & .009 \\
\hline Yes & 12 & $0.82(0.74-0.90)$ & 46.7 & .04 & 16 & $0.76(0.67-0.86)$ & 42.3 & .04 \\
\hline \multicolumn{9}{|l|}{ Physical activity } \\
\hline No & 10 & $0.87(0.74-1.01)$ & 23.6 & .23 & 12 & $0.76(0.68-0.84)$ & 52.9 & .02 \\
\hline Yes & 8 & $0.73(0.61-0.88)$ & 53.7 & .04 & 10 & $0.74(0.63-0.88)$ & 51.8 & .03 \\
\hline \multicolumn{9}{|c|}{ Lipid lowering medication use } \\
\hline No & 9 & $0.69(0.53-0.91)$ & 59.2 & .01 & 14 & $0.72(0.65-0.80)$ & 61.6 & .001 \\
\hline Yes & 9 & $0.85(0.77-0.93)$ & 3.6 & .41 & 8 & $0.83(0.73-0.93)$ & 0 & .62 \\
\hline
\end{tabular}

\section{Other lipid profiles parameters}

${ }^{a}$ Based on the DerSimonian and Laird random-effects model. 
(continued)

Table 4. Dose-Response Subgroup Analyses of Association Between High-Density Lipoprotein Cholesterol and Risk of Total Stroke and Ischemic Stroke, Systematic Review and Meta-Analysis of Prospective Cohort Studies

\begin{tabular}{|c|c|c|c|c|c|c|c|c|}
\hline \multirow[b]{2}{*}{ Characteristics } & \multicolumn{4}{|c|}{ Total Stroke } & \multicolumn{4}{|c|}{ Ischemic Stroke } \\
\hline & No. of Studies & Relative Risk (95\% Cl) & $t^{2}$ & $P$ Value $^{\mathrm{a}}$ & No. of Studies & Relative Risk (95\% Cl) & $I^{2}$ & $P$ Value ${ }^{a}$ \\
\hline No & 10 & $0.84(0.69-1.03)$ & 55.2 & .02 & 12 & $0.75(0.67-0.84)$ & 61.0 & .003 \\
\hline Yes & 8 & $0.77(0.69-0.86)$ & 0 & .47 & 10 & $0.75(0.64-0.87)$ & 34.9 & .13 \\
\hline
\end{tabular}

a Based on the DerSimonian and Laird random-effects model. 